\title{
Evaluation of the Results of Conservative Management of Women with Tuboovarian Abscess; Single Tertiary Center Experience
}

\author{
Cenk YASA ${ }^{1}$, Özlem DURAL ${ }^{1}$, Ercan BASTU ${ }^{1}$, Harika YUMRU ${ }^{1}$, Ömer DEMİR ${ }^{1}$, Funda GÜNGÖR UĞURLUCAN ${ }^{1}$ \\ Istanbul, Turkey
}

\begin{abstract}
OBJECTIVE: To evaluate results of patients with conservative management of tuboovarian abscess (TOA).

STUDY DESIGN: A retrospective cohort study of women with TOA. Between January 2012 and February 2015, all women that hospitalized with diagnosis of TOA enrolled in this study. Cases were analyzed with respect to age, parity, medical conditions, history of intra-uterine device use, size of TOA, Creactive protein (CRP) levels, white blood cell (WBC) count, CA-125 levels, antibiotic usage, hospitalization period.
\end{abstract}

RESULTS: Thirty-nine patients with TOA included in to this study. Mean age was $38.2 \pm 11.5$ years. Mean size of TOA was $5.7 \pm 2.1 \mathrm{~cm}$. In comparison between patients with abscesses $\leq 6 \mathrm{~cm}$ or $>6 \mathrm{~cm}$, TOA size is not associated with important outcomes including duration of antibiotherapy and duration of hospitalization.

CONCLUSION: Women with TOAs should be admitted to the hospital and immediately started in parenteral antibiotics. Due to high levels of success with antibiotherapy, immediate surgical management should always be performed in cases of rupture.

Keywords: Tuboovarian abscess, Antibiotherapy, Conservative management

Gynecol Obstet Reprod Med 2016;22(2):90-93 DOI: 10.21613/GORM.2016.67

\section{Introduction}

Tuboovarian abscess (TOA) is an occasional end result of pelvic inflammatory disease (PID) which is a polymicrobial ascending infection that causes endometritis, salpingitis, pelvic peritonitis (1). Several risk factors for the development of PID which include younger age of starting sexual intercourse, high number of sexual partners, decrease in use of barrier contraception and infection with chlamydia or gonorrhea (2). Also the risk factors for TOA are similar to those of PID, including multiple sex partners, age between 15 and 25 years, and a prior history of PID. Although majority of women with PID do not develop TOA, there is still controversy about why some women with PID develop TOA. Prior PID infection, delay in treatment and virulence factors of pathogens are the main risk factors about formation TOA (3). Ascending infection to the fallopian tube causes endothelial damage and edema of the infundibulum which results in tubal blockage. Ovaries might be

\footnotetext{
${ }^{I}$ Istanbul University Istanbul School of Medicine Department of Obstetrics and Gynecology, Istanbul

Address of Correspondence: Cenk Yasa

Istanbul University School of Medicine,

Department of Obstetrics and

Gynecology, Capa, Istanbul, Turkey

cenk_yasa@yahoo.com

Submitted for Publication:

18. 04.2016

Accepted for Publication:

27. 04.2016
}

affected through invasion of organisms via ovulation site. Also a TOA may also develop from local spread of infection associated with uncontrolled inflammatory disease of bowel, appendicitis, or adnexal surgery. Similar with PID, TOAs are also polymicrobial origin with a mixture of aerobic and anaerobic organisms. The most common isolated organisms for TOAs are E.coli, Bacteriodes species, Peptostreptococus, Peptococus and aerobic streptococcus $(3,4)$.

Management of TOAs largely depends on the status of patient and size of the abscess. When TOAs are diagnosed antibiotics should be initiated promptly. Also the suspicion of rupture of TOA requires urgent surgical intervention. In the case of TOAs without evidence of rupture the role for drainage and operative management of TOA is less clear. Antimicrobial therapy alone is usually effective in $70 \%$ of all cases of TOAs (3-6). Proper antimicrobial therapy of TOAs includes antibiotic regimens with activity against anaerobic bacteria in addition to an ability to penetrate abscess cavities while remaining stable in an acidic, hypoxic abscess environment. The need for surgical intervention is related to the size of the TOAs with $60 \%$ of those women with abscesses $10 \mathrm{~cm}$ or greater in diameter, $30 \%$ of those measuring 7 to $9 \mathrm{~cm}$, and only $15 \%$ of those 4 to $6 \mathrm{~cm}$ in diameter needing surgery (7).

We aimed to evaluate the results of conservative management in women with TOA. 


\section{Material and Method}

We performed a retrospective review of women with TOA, who were hospitalized and given parenteral antibiotic therapy in Istanbul University Istanbul Faculty of Medicine, Department of Obstetrics and Gynecology between January 2012 and February 2015. Inclusion criterias were (1) presence of an inflammatory mass in the pelvis, (2) age greater than 18 years, (3) abscess not requiring surgical intervention. Cases were analyzed with respect to age, parity, medical conditions, history of IUD use, smoking history, reason presenting for care, information at admission, size of TOA, C-reactive protein (CRP) levels, white blood cell (WBC) count, CA-125 levels, antibiotic usage, hospitalization period.

Imaging was obtained in almost all cases and included ultrasound (USG), computed tomography (CT) and magneticresonance imaging (MRI). Mean TOA diameter had been measured in two dimensions. Fever was defined as a temperature greater than $38.2{ }^{\circ} \mathrm{C}$. The initial antibiotic regimens were categorized to include at least (1) gentamycin and clindamycin, (2) ceftriaxone and metronidazole, (3) ciprofloxacin and metronidazole, and (4) others.

We created two abscess group based on maximal diameter of abscesses: $\leq 6 \mathrm{~cm}$ and $>6 \mathrm{~cm}$. If bilateral abscesses were noted, we used the larger of the two to quantify the size of abscess. Women with large and small abscesses compared by duration of hospitalization, days of febrile status, and antibiotherapy duration.

Statistical analysis was performed with SPSS software (Statistics Package for Social Sciences) version 16. Variables were presented with descriptive statistics as mean \pm SD for continuous variables and number and percentage for categorical variables. Difference in mean values and characteristics between groups were analyzed with independent samples t-test.

\section{Results}

A total of 51 patients with TOA were identified. We excluded 12 patients who underwent surgery for TOA which include drainage, salpingectomy, salpingo-oopherectomy and total abdominal hysterectomy and bilateral salpingo-oopherectomy. A final total 39 patients were included in the study. Mean age was 38.2 \pm 11.5 years (range 19-68 years). The demographic and clinical characteristics of the patients are summarized in Table 1.

There were 8 patients $(20.5 \%)$ who had current usage IUDs. Only 6 subjects (15.4\%) had concomitant medical problems that could contribute indirectly to abscess formation; 4 with diabetes mellitus and one with chronic hepatitis $\mathrm{C}$ and also one with renal insufficiency.

Mean size of TOA was $5.7 \pm 2.1 \mathrm{~cm}$ (range $2.1-8.8 \mathrm{~cm}$ ). 13 patients $(33.3 \%)$ were found with bilateral abscess. On admission laboratory evaluation revealed the mean CRP level was $151.8 \pm 118.2 \mathrm{mg} / \mathrm{dL}$ (range $11-458 \mathrm{mg} / \mathrm{dL}$ ), the mean WBC level $12.1 \pm 5.5103$ cells $/ \mu$ l (range 4800 - 22400) and the mean Ca-125 level was $58.2 \pm 57.1 \mathrm{U} / \mathrm{mL}$ ( range $14-186$ ). The most common reason for presentation was pain $(87.1 \%)$ and followed by abnormal discharge (38.5\%) and abnormal bleeding $(15.4 \%)$. Also on admission 14 patients $(35.9 \%)$ were febrile. On pelvic examination uterine tenderness was found in 21 patients $(53.8 \%)$, adnexal tenderness was found in 26 patients $(53.8 \%)$, and cervical motion tenderness was found in 23 patients $(58.9 \%)$.

Table 1: Demographic and clinical characteristics of patients

\begin{tabular}{|c|c|}
\hline \multicolumn{2}{|l|}{ Characteristics } \\
\hline Age, years, mean $\pm S D$ & $38.2 \pm 11.5$ \\
\hline Parity, numbers, mean \pm SD & $1.8 \pm 1.7$ \\
\hline \multicolumn{2}{|l|}{ Vaginal birth, $\mathrm{n}$, percentage } \\
\hline 0 & $15(38.5 \%)$ \\
\hline$\geq 1$ & $24(61.5 \%)$ \\
\hline \multicolumn{2}{|l|}{ Cesarian section, $n$, percentage } \\
\hline 0 & $31(79.5 \%)$ \\
\hline$\geq 1$ & $8(20.5 \%)$ \\
\hline \multicolumn{2}{|l|}{ IUD, $n$, percentage } \\
\hline Present & $8(20.5 \%)$ \\
\hline Absent & $31(79.5 \%)$ \\
\hline \multicolumn{2}{|l|}{ Chronic illness, $n$, percentage } \\
\hline Present & $6(15.4 \%)$ \\
\hline Absent & $33(84.6 \%)$ \\
\hline \multicolumn{2}{|l|}{ Smoking history, $\mathrm{n}$, percentage } \\
\hline Yes & $29(74.4 \%)$ \\
\hline No & $10(25.6 \%)$ \\
\hline \multicolumn{2}{|c|}{ Reason presenting for care, $n$, percentage } \\
\hline Pain & $34(87.1 \%)$ \\
\hline Abnormal discharge & $15(38.5 \%)$ \\
\hline Abnormal bleeding & $6(15.4 \%)$ \\
\hline \multicolumn{2}{|l|}{ Information at admission, $\mathrm{n}$, percentage } \\
\hline Fever & $14(35.9 \%)$ \\
\hline Uterine tenderness & $21(53.8 \%)$ \\
\hline Adnexal tenderness & $26(66.7 \%)$ \\
\hline Cervical motion tenderness & $23(58.9 \%)$ \\
\hline WBC, $10^{3}$ cells $/ \mu \mathrm{l}$, mean \pm SD & $12.1 \pm 5.5$ \\
\hline $\mathrm{CRP}, \mathrm{mg} / \mathrm{dL}$, mean $\pm \mathrm{SD}$ & $151.8 \pm 118.2$ \\
\hline $\mathrm{CA}-125, \mathrm{U} / \mathrm{ml}$, mean $\pm \mathrm{SD}$ & $58.2 \pm 57.1$ \\
\hline Unilateral abscess, $n$, percentage & $26(66.7 \%)$ \\
\hline Abscess size, $\mathrm{cm}$, mean $\pm \mathrm{SD}$ & $5.7 \pm 2.1$ \\
\hline \multicolumn{2}{|l|}{ (Note: range $=2.1-8.8$ ) } \\
\hline Antibioteraphy duration, days, mean \pm SD & $10.9 \pm 4.2$ \\
\hline Hospitalization, days, mean \pm SD & $10.6 \pm 4.0$ \\
\hline
\end{tabular}

Comparison was made between those patients with abscesses $\leq 6 \mathrm{~cm}$ or $>6 \mathrm{~cm}$ (Table 2 ). Of these 39 patients with a TOA $29(74.4 \%)$ had an abscesses $\leq 6 \mathrm{~cm}$ and 10 (25.6\%) had an abscesses $>6 \mathrm{~cm}$. There was no significant difference between groups in duration of febrile, duration antibiotic usage and duration of hospitalization. 
Table 2: Laboratory evaluation and outcomes by abscess size

\begin{tabular}{|c|c|c|c|}
\hline Characteristics & $\begin{array}{l}\text { TOA } \leq 6 \mathrm{~cm} \\
(\mathrm{n}=29)\end{array}$ & $\begin{array}{l}\text { TOA }>6 \mathrm{~cm} \\
(\mathrm{n}=10)\end{array}$ & $\begin{array}{l}\mathrm{p} \\
\text { value }\end{array}$ \\
\hline Days febrile, mean \pm SD & $2.1 \pm 2.9$ & $2.4 \pm 3.2$ & .64 \\
\hline Antibioteraphy duration, days, mean \pm SD & $10.5 \pm 4.1$ & $11.2 \pm 4.4$ & .20 \\
\hline Hospitalization, days, mean \pm SD & $10.2 \pm 3.9$ & $10.9 \pm 4.1$ & .38 \\
\hline
\end{tabular}

Patients were then evaluated by initial antibiotic regimen. Twenty-six patients $(66.7 \%)$ were initially placed on regimens containing gentamycin and clindamycin, 5 patients $(12.8 \%)$ were ceftriaxone and metronidazole, 3 patients $(7.7 \%)$ were ciprofloxacin and metronidazole and 5 patients $(12.8 \%)$ were other antibiotic regimens.

\section{Discussion}

Historically, treatment of TOA was thought to require hysterectomy and bilateral salphingoopherectomy. Although this approach offered high cure rates, it was at the cost of high rates of surgical complications, infertility and hormone deficiency (8). Medical treatment with broad spectrum antibiotics is currently considered as initial management for unruptured TOAs (9). With the advent of effective antimicrobial therapy, operative management has become much more conservative moving toward procedures that allow sparing of ovarian function and if possible can even be considered in cases of rupture (4). However, optimal treatment of TOAs still remain unclear. Women with TOA should have direct inpatient observation for at least 24 hours because risk of abscess rupture and sepsis.

Especially the antibiotic regimens who provide broad coverage for not only $N$. gonorrhoeae, C. trichomatis and M. genitaleium, but also for streptococcus, Gram-negative enteric bacteria and bacteria vaginosis-associated anaerobic organisms are recommended (10-13). For the treatment of TOA, when comparing the first-line parenteral antibiotic regimens, none of the regimens have been shown to be superior $(3,4,14)$. In animal models, regimens including clindamycin, metronidazole and cefoxitin were shown superior abscess wall penetration and activity within cavity (15). In a series of 232 patients with TOA that clindamycin plus gentamicin (68\%) was more effective than penicillin and gentamicin (49\%) for reduction of TOA size, highlighting the importance of anaerobic coverage with clindamycin (16).

Regarding antibiotic regimens for TOA, Weisenfeld and Sweet reported the response rates of TOAs to medical therapy and showed a $72 \%$ success rate in patients treated with clindamycin and aminoglycoside versus $82 \%$ success rate in patients treated with cefoxitin or cefotetan and doxycycline (3). In contrast, McNeeley et al found this regimen to be less successful (17).

We found that TOA size is not associated with important outcomes including duration of antibiotherapy, duration of febrile, and duration of hospitalization. Gjeiland et al. noted that treatment success was not affected by the size of abscess (18). In contrast, DeWitt et al. found that TOA size was associated with more complications, longer duration of hospitalization as well as increased an increased need for surgery (19). Thus, it is reasonable to initiate antibiotics alone in women who are hemodynamically stable. In addition, in any postmenopausal women with an abscesses, because malignancy is a concern aggressive surgical management should be considered. Protopapas et al showed that 8 of 17 (47\%) postmenopausal women had an underlying malignancy as compared with 1 of 76 premenopausal women (1.3\%) (20).

Main limitation of our study, only hospitalizations linked with a primary diagnosis of TOA were included. For this reason, our database does not include patients with TOA treated in outpatient setting, our study does not provide true incidence of this conditions.

As a conclusion, women with TOAs should be hospitalized and started IV broad spectrum antibiotics. Immediate surgical management should always be performed in cases of rupture, because of high cure rates with broad spectrum antibiotics in unruptured cases. Correct decision of therapy will be helpful for patient in reducing morbidity, adhesions, need for radical surgery and conservation of fertility.

\section{References}

1. Workowski KA, Berman S. Sexually transmitted disease treatment guidelines, 2010. MMWR Recomm Rep 2010; 59:1-110.

2. Jossens MO, Eskenazi B, Schachter J, Sweet RL. Risk factors for pelvic inflammatory disease. A case control study. Sex Transm Dis 1996;23:239-47.

3. Wiesenfeld HC, Sweet RL. Progress in the management of tuboovarian abscesses. Clin Obstet Gynecol 1993;36:43344.

4. Landers DV, Sweet RL. Tubo-ovarian abscess: contemporary approach to management. Rev Infect Dis 1983;5:87684.

5. Hiller N, Sella T, Lev-Sagi A, Fields S, Lieberman S. Computed tomographic features of tuboovarian abscess. J Reprod Med 2005;50:203-8.

6. Gingsburg DS, Stern JL, Hamod KA, Genadry R, 
Spemnce MR. Tuboovarian abscess: a retrospective review. Am J Obstet Gynecol 1980;138:1055-8

7. Reed SD, Landers DV, Sweet RL. Antibiotic treatment of tuboovarian abscess: comparison of broad-spectrum betalactam agents versus clindamycin-containing regimens. Am J Obstet Gynecol 1991;164:1556-162.

8. Kaplan AL, Jacobs WM, Ehresman JB. Aggressive management of pelvic abscess. Am J Obstet Gynecol 1967; 98:482-7.

9. Sweet RL Tubo-ovarian abscess. Pelvic Inflammatory Disease, pages 101-124, Taylor \& Francis, London, UK, 2006.

10. Dodson MG. Antibiotic regimens for treating acute pelvic inflammatory disease. An evaluation. J Reprod Med 1994; 39:285-96.

11. Landers DV, Wolner-Hanssen P, Paavonen J, et al. Combination antimicrobial therapy in the treatment of acute pelvic inflammatory disease. Am J Obstet Gynecol 1991;164:849-58.

12. Walker CK, Landers DV, Ohm Smith MJ, et al. Comparison of cefotetan plus doxycycline with cefoxitin plus doxycycline in the inpatient treatment of acute salpingitis. Sex Transm Dis 1991;18:119-23.

13. Brunham RC, Binns B, Gujon F, et al. Etiology and outcome of acute pelvic inflammatory disease. J Infect Dis 1988;158:510-17.
14. Sweet RL, Gall SA, Gibbs RS, et al. Multicenter clinical trials comparing cefotetan with moxolactam or cefoxitin as therapy for obstetrics and gynecologic infections. Am J Surg 1988;155:56-60.

15. Joiner KA, Lowe BR, Dzink JL, Bartlett JG. Antibiotic levels in infected and sterile subcutaneous abscesses in mice. J Infect Dis 1981;143:487-94.

16. Reed SD, Landers DV, Sweet RL. Antibiotic treatment of tuboovarian abscess: comparison of broad-spectrum betalactam agents versus clindamycin-containing regimens. Am J Obstet Gynecol 1991;164:1556-61

17. McNeeley SG, Hendrix SL, Mazzoni MM, Kmak DC, Ransom SB. Medically sound, cost-effective treatment for pelvic inflammatory disease and tuboovarian abscess. Am J Obstet Gynecol 1998;178:1272-8.

18. Gjeiland K, Ekerhovd E, Granberg S. Transvaginal ultrasound guided aspiration for treatment of tubo-ovarian abscesses: a study of 302 cases. Am J Obstet Gynecol 2005;193:1323-30.

19. DeWitt J, Rieining A, Allsworth JE, Peipert J. Tuboovarian abscesses: Is size associated with duration of hospitalization \& complications? Obstet and Gynecol Int 2010;2010:847041.

20. Protopapas AG, Diakomanolis ES, Milingos SD, et al. Tubo-ovarian abscesses in postmenopausal women: gynecological malignancy until proven otherwise? Eur J Obstet Gynecol Reprod Biol 2004;114:203-209. 